\title{
Proyecto Enfocadas: "una experiencia grupal realizada con mujeres que sufrieron en el pasado violencia por parte de sus parejas, utilizando la fotografía y la narración como herramienta terapéutica"
}

\author{
Marcela LOCKETT DESTRI ${ }^{1}$ \\ marcelapsicoterapia@gmail.com
}

Recibido: 01/07/13

Aceptado: 21/11/13

\section{RESUMEN}

Es objetivo del presente trabajo compartir la experiencia del Proyecto Enfocadas, desarrollado en Madrid, España, en un servicio del Ayuntamiento que atiende a víctimas de violencia de género. Las destinatarias directas del proyecto han sido 10 mujeres que han vivido en el pasado violencia por parte de su pareja, logrando salir de dicha situación tras un proceso terapéutico.

Estas mujeres participaron en 17 talleres grupales mediante el uso de la fotografía y la escritura. Los objetivos de los talleres fueron fomentar la creación artística, contribuir al desarrollo personal tendiendo a la integración de la historia vital así como el desarrollo de la autoestima y el empoderamiento como colectivo, al darles voz y protagonismo a las participantes. Nos planteamos en una segunda etapa, sensibilizar a la población en torno a la problemática de la violencia de género desde el mensaje de las protagonistas y desde la prevención a través de la muestra de su producción artística.Es objetivo de este trabajo indagar sobre el uso de la fotografía y narración como herramienta terapéutica ${ }^{2}$, mostrando momentos significativos del proceso grupal, así como resultados del proceso en la voz de las protagonistas.

Palabras clave: violencia de género; integración bilateral; integración de sucesos traumáticos a la historia vital; proceso grupal; proceso creativo y narrativo. Fotografía y escritura.

\footnotetext{
${ }^{1}$ Psicóloga, psicoterapeuta del Punto Municipal de Violencia de Género del Ayuntamiento de Madrid. Coordinación y ejecución del proyecto, junto a Eva Sala, fotógrafa, creadora de Nophoto Voz.

http://enfocadasvoz.blogspot.com.es/

www.marcelalockett.com

${ }^{2}$ Equiparo el concepto de terapéutico al de Mindsight (Daniel Siegel, 2013), en palabras del autor: "no sólo supone sentir el presente: también supone conocer a fondo el pasado para no acabar prisioneros de elementos de nuestra experiencia que aún no se han analizado y nos pueden limitar en un futuro. Entender el pasado nos libera y nos permite estar presentes en nuestra vida y convertirnos en autores creativos y activos de nuestra historia futura".
} 


\title{
Referencia normalizada
}

LOCKETT M. (2014). "Proyecto Enfocadas: una experiencia grupal realizada con mujeres que sufrieron en el pasado violencia por parte de sus parejas, utilizando la fotografía y la narración como herramienta terapéutica". En Arteterapia: Papeles de arteterapia y educación artística para la inclusión social Vol.: 9. Páginas 225-246. Madrid.

\section{Project: Women in Focus}

"The experience of a group of women who have suffered violence at the hands of their partners, use photography and storytelling as a therapeutic tool."

\begin{abstract}
The objective of this paper is to share the experience gained by the "Women In Focus" (Proyecto Enfocadas) project in Madrid (Spain) which was organised by a department of the city council which serves victims of domestic violence. The target group of the project was 10 women who in the past had experienced violence from their partners and the project describes how they recovered from this situation through therapy.
\end{abstract} They participated in 17 group workshops which used photography and writing. The objectives of these workshops tended to promote artistic creation, personal development, the integration of their life histories and the development of self-esteem and empowerment by giving a collective voice to the participants. Consideration was given in the second stage to the raising of awareness about the issue of gender violence through the message of the participants and on prevention through samples of their artistic work. The objective of this paper is to investigate the use of photography and storytelling as a therapeutic tool, showing significant moments of the group process and results of the process in the voice of the protagonists.

Key words: gender violence, bilateral integration, explicit implicit memory, integration of traumatic events in one's life history, the group process, the creative process and narratives. Photography and writing.

\section{Descripción de la experiencia}

Enfocadas ha sido un proyecto desarrollado entre marzo y julio del 2013 en el Punto Municipal del Observatorio de Violencia de Género $\mathrm{n}^{\mathrm{o}} 1$, dependiente de la Dirección General de Igualdad de Oportunidades del Ayuntamiento de Madrid. Este es un servicio especializado de atención a mujeres víctimas de violencia de género perpetrada por sus parejas o ex parejas, a quienes se brinda atención integral para su recuperación y protección. Esta experiencia concreta ha sido posible gracias a la subvención de la Fundación Obra Social La Caixa. Fue coordinado por una psicóloga psicoterapeuta de la institución y una fotógrafa. Se 
contó con la colaboración de una especialista en escritura y otras colaboradoras en algunas sesiones: estimulación sensorial, relato de la trayectoria de una artista ${ }^{3}$.

Las destinatarias directas del proyecto han sido diez mujeres que han vivido violencia de género y que lograron salir de dicha situación; las mismas habían finalizado con anterioridad un proceso terapéutico, en el área de psicología del PMVG, que ha contribuido a su recuperación y a tomar el control de sus vidas, dejando la violencia atrás, en el pasado. Las mujeres participaron en un proceso de 17 talleres grupales que se llevaron a cabo con frecuencia semanal, de expresión visual y escrita, así como de desarrollo personal. Los objetivos de los mismos fueron:

- Fomentar la creación artística fotográfica y de escritura.

- Favorecer la integración de aspectos traumáticos, permitiéndoles asumir las formas de violencia vividas como parte del pasado, pasando a ser sólo una parte de su historia vital.

- Mejorar las habilidades sociales, fortalecer vínculos afectivos, seguros en el trabajo grupal.

- Contribuir al desarrollo personal y bienestar emocional.

- Contribuir al desarrollo de la autoestima y empoderamiento como colectivo.Por otro lado, nos planteamos como destinataria indirecta a la población en general, en una segunda etapa, donde pueda mostrarse su producción. El objetivo de esta segunda etapa es sensibilizar a la población en torno a la problemática de la violencia de género desde el mensaje de las propias mujeres protagonistas y desde la posibilidad de

la prevención y la recuperación de las víctimas.Como resultados concretos del trabajo de los talleres, surge la creación de libros de artistas individuales de las protagonistas en los que se plasme el resultado del proceso: el de un tema fotográfico escogido por cada mujer; la elaboración de postales con las imágenes que ellas seleccionen de su trabajo y un mensaje sobre la violencia y la superación, y finalmente, la muestra a nivel comunitario del trabajo realizado (segunda etapa del proyecto en fase de ejecución).

\footnotetext{
${ }^{3}$ Proyecto subvencionado por la Fundación Obra Social La Caixa en la Convocatoria de Arte para la mejora social 2013, presentada por la artista Eva Sala, fotógrafa.Contamos con Esther Ramón encargada de impartir los cuatro talleres de escritura.; la participación de una educadora, Eva Salas que coordinó el taller de estimulación sensorial y Ainoa Valle como fotógrafa invitada que vino a contar al espacio su experiencia y trabajo como artista; compañeras psicólogas del Punto Municipal: Carmen Lamana y Mercedes Sánchez para la narración en pequeños grupos de la fotobiografia.
} 


\section{Metodología utilizada}

La metodología utilizada fue la de taller, entendiendo éste como un espacio participativo de aprendizaje, grupal, cuyos participantes asumen un papel activo, aportando sus conocimientos y experiencias. Agruparse con otras mujeres contribuye a la toma de conciencia de que la violencia es un problema social al que han estado expuestas por el mero hecho de ser mujeres. A su vez contribuye a compartir logros y soluciones, y a reconocerse como colectivo. Permite la reflexión conjunta, el intercambio de experiencias, el autoconocimiento y el apoyo mutuo.

El rol de las coordinadoras se centra en potenciar la escucha activa, la interacción, la comunicación y la participación de los integrantes, más que de un lugar de saber. La planificación de las sesiones, centradas en un tema o tarea a trabajar, así como la flexibilidad a la hora de su desarrollo en función del devenir grupal, es fundamental.

Los talleres se iniciaron con actividades que tendían a la motivación de las participantes, el contacto con la cámara fotográfica como herramienta de trabajo, y al contacto con la escritura. Se realizaron cuatro talleres específicos con el objeto de estimular la creatividad; el sentir más que el pensar. (realización de gymkhana sensorial, gymkhana fotográfica). Las participantes se prepararon para el trabajo que realizarían por medio de la técnica de la fotobiografía (Fina Sanz, 2007). Se generó un proceso de búsqueda de fotografías de su historia (diferentes etapas vitales), su selección y elaboración de la línea de vida en el cuaderno de artista. También se trabajaron ejemplos de otras mujeres que utilizaron la fotobiografía para analizar su vida, así como ejemplos de "mind mapping" y la narración en pequeños grupos de la misma siempre en primera persona.

Una vez que el pasado fue abordado, comenzamos a centrarnos en el "aquí y ahora" y en los planes futuros: sus sueños y proyectos a partir de una vida sin violencia.

La presentación del trabajo de diferentes artistas como Yolanda Domínguez, Jo Spencer, Adriana Lestido, entre otras, permitió mostrarles cómo podemos hablar de nosotras a través de nuestras imágenes y denunciar problemas sociales e injusticias.

Por medio de pequeñas consignas, las mujeres comenzaron a tomar sus primeras fotografías y escribir sus textos tomando contacto con su interior, "su yo reflexivo" y compartiéndolo en el grupo. A partir de encargos concretos como fotografiar un día cotidiano, hacer un autorretrato, fotografiar un objeto que te represente tu mujer ideal, trajeron sus producciones a las sesiones permitiendo en el visionado hablar de ellas en primera persona. Hablar de los cambios en su vida a partir de una vida sin violencia

Trabajamos con "lluvia de ideas" los temas posibles de sus proyectos personales. El mismo proceso llevó a que cada una, con el trabajo grupal y la orientación de las coordinadoras, llegase a vislumbrar el tema del que querían que fuese su proyecto fotográfico. 
La palabra acompañó dicho proceso al contarnos las fotografías que traían, así como los textos que elaboraban para acompañarlas, encontrándose todo ello plasmado en los libros de artistas.

Intentaremos en este trabajo ahondar en el por qué de la utilización de la fotografía y la narración combinadas, tanto desde la elaboración de un marco teórico, como a través de las viñetas de algunas sesiones realizadas. A su vez, destacaremos algunos resultados y producción de las mujeres.

\section{Marco teórico: ¿por qué el uso de la combinación de fotografía y narración?}

"Si se mide la autenticidad de la expresión a través de la expresión verbal y la expresión en imágenes, es muy probable que la expresión en imágenes supere a los resultados verbales, debido a la flexibilidad que tiene la imagen sobre la palabra. Las imágenes mentales actúan sobre el sistema nervioso autónomo, donde las palabras y las órdenes verbales y conceptuales no tienen acceso". (Martina Charaf, 2012)

Partiendo de un marco más amplio, social, destacamos como características del lenguaje visual:

- Que es un lenguaje en sí mismo, al decir de Walker Evans: "las fotografías no son ilustrativas. Ellas y el texto son iguales entre sí, mutuamente independientes y colaboradoras totales" (W Evans, 1993).

- "Que existe interrelación entre tres sujetos potenciales en la fotografía: el fotógrafo, el fotografiado y el espectador". (Roland Barthes)

- Que la visión del fotógrafo, es subjetiva y emocional. "La fotografía explicita la subjetividad que el acto humano conlleva. Es por esto que el paradigma comunicativo visual es probablemente una de las expresiones más claras de la necesidad de volver a valorar la singularidad de la emoción de forma socialmente aceptada." (Heura Posada Pie, 2011)

- Que la visión del espectador está abierta a los múltiples significados e interpretaciones atribuibles a una misma fotografía. "La potencialidad de interpretación subjetiva que el medio fotográfico contiene. Este es un valor propio e intrínseco del material fotográfico y visual”. (Heura Posada Pie, 2011).

Estas características coinciden si las pensamos en un nivel micro, en experiencias grupales e individuales que tienden al autoconocimiento de los protagonistas. Judy Weiser ${ }^{4}$ lo describe de la siguiente manera: "Cada fotografía que una persona toma es también una forma de autorretrato, una especie de "espejo con memoria" que refleja aquellos momentos que fueron suficientemente especiales para ser congelados en el tiempo para siempre. En su conjunto estas fotos hacen

\footnotetext{
${ }^{4}$ Ver en: http://www.phototherapy-centre.com/home.htm
} 
visibles las historias que acontecieron en la vida de la persona sirviendo como huellas que han marcado donde ha estado (tanto emocionalmente como físicamente) y quizás estén señalando hacia donde está encaminándose próximamente".

Coincide en que "al observar una fotografía, las personas crean significado que ellos creen esta proviniendo de la foto misma y este significado puede o no ser el que el fotógrafo originariamente intentó expresar. Entonces el mensaje emocional depende de quien esta mirando. Porque las percepciones y experiencias de vida encuadran y definen lo que se ve como real. Las reacciones hacia las fotos pueden revelar mucho acerca de ellos mismos".

"A nivel terapéutico, las fotos que traen los pacientes actúan como símbolos concretos de sí mismos y objetos metafóricos transicionales, que silenciosamente ofrecen una forma de mirar hacia el interior de ellos mismos de una manera que los métodos verbales no pueden totalmente representar o construir". (Judy Weiser)

Estamos hablando a mi manera de entender del valor proyectivo ${ }^{5}$ que tiene tanto el acto creativo de fotografiar, como del interpretar una fotografía, atribuimos significado a las producciones desde nuestro marco interno y personal, desde nuestras vivencias, experiencias y significaciones que atribuimos al mundo que nos rodea.

Considero que mi acercamiento al uso de la fotografía como herramienta terapéutica, proviene de mi experiencia como psicoterapeuta en el uso de las nuevas herramientas terapéuticas basadas en los estudios de neurociencias utilizadas en mi práctica en los últimos años. Ejemplos de ello son la "Integración del Ciclo Vital" (Peggy Pace, 2002) "EMDR" (Francisce Shapiro, 1989), "Imaginaría Guiada" . Lo común en ellas ${ }^{7}$ es la utilización de "imágenes mentales" a manera de fotografías, las cuales pueden proceder de recuerdos vividos en el pasado, así como de escenas nuevas, imaginadas, que se tienden a potenciar bien para la búsqueda de soluciones, bien para dotar de recursos personales a un sujeto. En el uso de las mismas, en la repetición de las imágenes o en realizar cambios en imaginación, se produce la conexión con nueva información que permite un cambio en la memoria, en la significación que se le atribuye por ejemplo a un hecho traumático.

\footnotetext{
${ }^{5}$ Anderson define a la proyección como: "lanzar hacia fuera algo propio (algo que ya tengo), están implicados procesos mentales internos, proceso por medio del cual ha llegado a dar esa respuesta, por ello es necesario analizar el contenido y la estructura".

${ }^{6}$ para más información sobre las mismas ir a:

http://www.emdr-es.org/emdr.htm

http://www.integraciondelciclovital.es/

Imagery rescripting and reprocessing therapy (IRRT). International Trauma Institute Press.

${ }^{7}$ El utilizar imágenes mentales es sólo un detalle de las técnicas nombradas, ya que por ejemplo EMDR se basa como su nombre lo dice en el uso de estimulación bilateral. Se sugiere consultar las páginas sugeridas.
} 
De Prado (1991) distingue tres tipos de imágenes mentales principales que están en juego en la técnica de Imaginería guiada que desarrolla:

-Las imágenes eidéticas: expresan detalles nítidos y vivos. Generalmente provienen de la infancia.

-Memorias Evocativas: son imágenes que expresan el recuerdo de eventos y vivencias ya pasadas. En función del impacto que cada una haya tenido su registro será más o menos nítido, fuerte y completo.

-Las imágenes de la imaginación y de la fantasía: imágenes que ocurren espontáneamente y que pueden ser expresadas y fijadas con sentido y orden a través de un proceso de imaginaria guiada. Son un reservorio de respuestas y soluciones a situaciones y problemas. Cuando el contenido de la imaginaciones concreta en un producto determinado puede definir y dar nacimiento a un invento o creación novedosa.

Para Damasio,(A Damasio,1999) el pensamiento humano funciona siempre por imágenes. La mente no puede dejar de funcionar sin un soporte imaginativo que está presente siempre, aun en los momentos aparentemente más abstractos.

Es el hemisferio derecho el que se maneja con sensaciones, imágenes y significados no verbales, y la capacidad de representar los estados mentales de los demás (empatizar y sintonizar con los otros).

$\mathrm{Si}$ asociamos el uso de la fotografía a esas imágenes mentales, material bruto de nuestra mente, podemos aportar a través de la escritura y la palabra su significado tendiendo a la integración de ambos hemisferios cerebrales.

El lado izquierdo del cerebro aporta la maquinaria cognitiva, el pensamiento narrativo. Es el "interprete de esos input". Es lingüístico y lógico. Nuestro objetivo sería lograr una mayor Integración a nivel bilateral: hemisferio izquierdoderecho. Ambas herramientas están en juego en el proceso de fotografiar y narrar.

Como antecedentes de la propuesta tomamos el uso de la imaginería guiada (Charaf Mariana, 2012): "el cerebro funciona simultáneamente en su totalidad. Mientras cada persona registra el mensaje, guión o relato verbal, lo incorpora en palabras a través del hemisferio cerebral izquierdo, luego ese mensaje es decodificado por el hemisferio cerebral derecho en imágenes, sensaciones, colores, texturas, aromas. Bajo estas condiciones óptimas de trabajo ambos lados del cerebro dividen responsabilidades para procesar, decodificar y producir conjuntamente".

"La vinculación entre palabra e imagen: ambas representan dos modos naturales pero muy diferentes de pensar. Si bien se enseña y entrena con mayor eficacia al pensamiento verbal, la verdad es que no hay dudas de que la forma más productiva de pensar es combinando ambas modalidades, es decir la lógica con la imaginación, a fin de utilizarlas de la manera más personal posible".

En palabras de D Glouberman (1991) "las palabras son la manera socialmente estructurada de pensar de forma lógica, analítica y realista y de comunicarnos eficazmente con los demás. Las imágenes son nuestra forma idiosincrática y 
personal de pensar de modo intuitivo, holístico y metafórico y de comunicarnos eficazmente con nosotros mismos".

Se ha estudiado a partir de los años 90 y llegado a la conclusión de que el cortex cerebral es capaz de reorganizarse a través de todo el ciclo de la vida. Hablamos de integración izquierda-derecha que "permite expresar los sentimientos con palabras, ser concientes de las emociones, e integrar las tendencias emocionales positivas y negativas" (Cozolino, 2006).

En la fundamentación del porque imaginar destacamos:

-que el cerebro no distingue entre la experiencia real e imaginada.

-la experiencia llevada a cabo por Pascual-Leone demostró que los movimientos imaginados creaban cambios en las redes neuronales en el mismo grado que lo harían los movimientos físicos reales."

Cuando narramos nuestras historias partiendo de dichas imágenes, tendemos a la integración narrativa, la misma se logra cuando "el sujeto crea un mapa global del sí mismo a lo largo del tiempo y en varios contextos. Esta integración lleva al fortalecimiento del yo central, que se manifiesta en un "sujeto flexible, que se adapta a situaciones, coherente, estable y energizado" (D Siegel, 2007) con metas y proyección de futuro.

La narración que surge de esta actividad pre-frontal también incluye un narrador, un tercero observador, por el cual podemos hablar de nosotros en tercera persona: puedo narrar mi existencia aunque esté experimentando mi vida directamente, como protagonista.

Daniel Siegel, en "La mente en desarrollo", expresa: "El relato de las historias desempeña un rol central en las culturas humanas. Entra en juego la memoria declarativa por la que recodamos acontecimientos experimentados en forma de historia. La co-construcción de la narración es un proceso fundamental estudiado por antropólogos en que las familias se unen para relatar historias de la vida cotidiana. La historia capta nuestra atención porque requieren que participemos en la construcción activa de la vida mental y experiencias de los personajes. Tal es así que una historia esta creada tanto por el narrador como por el oyente: "esta intrincada danza requiere que ambas personas tengan una compleja capacidad de leer las señales sociales, de compartir el concepto de existencia de una experiencia subjetiva de la mente y de estar de acuerdo con participar en normas del discurso socialmente aceptadas. Así se co-construyen socialmente las historias". (D Siegel).

Podemos pensar en torno a la experiencia grupal o en el proceso terapéutico, que el hecho de narrar con otros agrega un plus al proceso, tanto por ser testigo como al poder aportar nuevas dimensiones a lo narrado enriqueciendo así el

\footnotetext{
${ }^{8}$ Pascual-Leone, 1995. Modulation of muscle responses evoked by transcranial magnetic stimulation during the acquisition of new fine motor skills. Journal of neurophysiology 74 .
} 
proceso. El clima afectivo del momento de la narración, agrega la validación de la experiencia y de las emociones que se producen en el sujeto y puede ser reparador en la medida en que muchas veces esas experiencias pueden haber sido silenciadas o no comprendidas y juzgadas por los otros.

Por esa necesidad de favorecer la continuidad histórica, partimos del pasado para poder hablar y contar por medio de la palabra y las fotos sobre el presente, sueños y proyectos futuros. Para ello utilizamos la técnica de la fotobiografía (Fina Sanz, 2007).

Se generó un proceso previo de búsqueda de fotografías de su historia (diferentes etapas vitales), su selección, elaboración de la línea de vida en el cuaderno de artista, así como la narración en pequeños grupos de la misma en primera persona. Pensábamos que el proceso se daría en un clima de seguridad y confianza a nivel grupal, con procesos de identificación en las narraciones de las participantes por las historias vividas, llevando a ver el proceso como un problema social más que individual.

Tomando en cuenta la similitud, en parte, con el proceso de creación de una línea de tiempo de recuerdos ordenados cronológicamente, en la técnica de Integración del Ciclo Vital" destacamos que el proceso puede producir "un mapa espacio temporal del yo" que nos lleva a la recuperación e integración de más recuerdos a lo largo del proceso; la tendencia al surgimiento de recuerdos más positivos, agregándose nueva información que antes no estaba integrada o asociada. (destacamos la importancia de realizarlo en un proceso de grupo y en un clima de respeto y apoyo).

La idea de una narración única para la vida humana es muy limitada, porque nuestra memoria y nuestra naturaleza esta en constante cambio. A medida que sigamos cambiando como individuos a lo largo del tiempo, nuestras narraciones también evolucionarán como reflejo de la naturaleza dinámica de la vida y de las relaciones sociales, es decir, vamos percibiendo e interpretando la experiencia desde nuevos puntos de vista.

Damasio (Damasio, 1999) en relación a la memoria expresa: "es la emergencia evolutiva de los mecanismos neurales que hacen posible la memoria. A medida que las sensaciones pasadas pueden ser reactivadas y producir una sensación-imagen en el sujeto psíquico que va surgiendo, éste puede actualizar en un determinado momento, en el marco de la conciencia y ser central en el aquí y ahora, las sensaciones- imágenes pasadas y la imagen del sujeto en ellas. La sensación consecuente es que el sujeto psíquico siente la temporalidad o historia de su ser central. La integración del pasado es el primer paso evolutivo, asentado en la memoria. Pero el ser personal deberá completarse también mirando hacia el

\footnotetext{
${ }^{9}$ Destacamos diferencias en cuanto a que en el Protocolo Estándar de Integración del Ciclo Vital se hace hincapié en la repetición de la línea de tiempo por lo menos tres veces para el logro de la integración neuronal. Para mayor información consultar la página dada.
} 
futuro: cuando las imágenes registradas, al ser manipuladas incluso transformadas (cosa que los mecanismos neuronales acabarán haciendo posible) permitirán imaginar nuevas situaciones, objetivos, metas, planes y estrategias de acción todo ello en el marco de la más compleja actuación cognitiva"

La novedad fisiológica más destacada es la memoria de hechos. Múltiples generaciones de una simple "sensación de ser conociendo" aplicadas a ese algo por conocer, como a ese algo al que se le atribuye el conocimiento, complejo y eternamente revivido: el ser autobiográfico. La conciencia de ser que se genera, es en perspectiva individual al mismo tiempo conciencia de ser poseedor de las imágenes y conciencia de ser agente de las respuestas al medio".

Yolanda Calvo en la descripción de proceso de la Integración del Ciclo Vital expresa: "no podemos cambiar lo que ocurrió, pero sí podemos cambiar el sentido y significado que damos a lo vivido. Lógicamente, esto significará que según se despliegue nuestra vida, iremos incorporando en los recuerdos del pasado las vivencias de ese presente, que ahora es futuro, reinventándonos constantemente a nosotros mismos y dando sentido a lo vivido, entonces, con la conciencia del ahora".

"En relación a la capacidad de evocar y recuperar imágenes, es interesante tener en cuenta, que a menos que se trate de imágenes eidéticas, toda imagen que ha sido almacenada en la memoria perceptiva, sensorial o emocional, sufre algún tipo de modificación y cambio que corresponde al tratamiento particular que cada persona haga de ella y también al tiempo que lleva almacenada y al impacto (positivo o negativo) que produjo para la historia de cada persona.

Por ese motivo, pueden existir tantas representaciones de la realidad, como personas y como modalidades de procesamiento de la experiencia personal de cada individuo". Experiencias pasadas, el estado físico y emocional y los rasgos psicológicos de cada persona imprimen un sello particular a cada historia y a la lectura que de ella se hace.

Tomando en cuenta la interrelación entre imágenes mentales y palabra, destacamos el máximun posible de ese proceso: el llegar a un resultado "creativo", entendiendo al mismo como: "la capacidad de imaginar y fantasear sin limitaciones internas ni obstáculos externos. Es toda realización humana creadora de algo nuevo, ya se trate de reflejos de algún objeto del mundo exterior, ya sean determinadas construcciones del cerebro o del sentimiento que viven y se manifiestan solo en el propio ser humano". (Vigostki, 1982)

"Cada persona posee el potencial creativo de combinar, transformar y dar vida y realidad a nuevas creaciones ya sean estas imágenes, acciones o productos originales todos ellos auténticos y novedosos... todo proyecto parte de elementos y materiales que provienen y existen en el mundo real y sobre los cuales las personas han desarrollado un conocimiento profundo y detallado que les permite intervenir activamente en distintas direcciones y con intenciones variadas".

En el trabajo de Enfocadas, estaba en la mira el logro de un resultado creativo que se plasmaría en los proyectos fotográficos de cada participante, así como en el libro de artista individual, donde ellas escogerían al final del proceso qué 
contenidos visuales y escritos plasmar en él. Los diferentes ejercicios que se fueron desarrollando tendían a estimular esa creatividad estimulando los sentidos, mostrando el proceso creativo de otros artistas, estimulando el juego y el placer por descubrir esos recursos escondidos muchas veces y subestimados por ellas mismas.

\section{Desarrollo de la experiencia}

En este apartado queremos ilustrar a partir de viñetas registradas en forma de crónica de las sesiones, algunos de los conceptos desarrollados teóricamente.

El proceso de la técnica de la fotobiografía, cuyo resultado fue la elaboración de una línea de vida con las fotos seleccionadas por las participantes y su posterior narración en pequeños grupos. Esto comienza con el proceso mismo de elección de las fotos de diferentes etapas de la vida infancia, juventud, adultez.

La consigna se dio al inicio de las sesiones para darle tiempo a su búsqueda. Una vez realizado, dimos lugar a la expresión de las emociones que dicho proceso les produjo, a exponerlo en el grupo, por medio de elección de cartas con imágenes (cartas COPE-OH $)^{10}$ que presentan diferentes situaciones, emociones, etc.

En ese proceso de selección, las mujeres mostraron diferentes niveles de integración de la historia de violencia a su historia vital, expresándose en las emociones que les produjeron: "me fue indiferente y antes me causaba ansiedad"; "he estado angustiada y me he tenido que ir de la sesión", así como en lo relativo a qué fotos incluyen y cuáles se dejan de lado: "no tengo fotos, todas están en cajas, no puedo buscarlas"; "las fotos de él (se refiere al agresor) y esa etapa están rotas para siempre".

Una de las mujeres expresa ese cambio de la "ansiedad a la indiferencia" de la siguiente manera:

"Lo he pasado mal en el pasado. Al tener que escoger en la separación fue algo hasta traumático. No rompi las fotos en las que está él con sus hijas, no pude, se las guarde a sus hijas, y ahora están ahi olvidadas. He pasado desde no poder verlas, a no volver a hacerlo, y ahora a poder ir eligiéndolas.

Recuperé fotos antiguas, por ejemplo cuando era monitora de aeróbic.

He escogido el dibujo del laberinto para expresar lo que siento porque todavía estoy intentando salir del laberinto, pero a veces siento que sigo ahi. El tiempo yo creo que hace algo con el tema. Que pase. La carta con la imagen de una ventana abierta, una cara que sale de la jaula, un pájaro volando, representan para mi que ya no estoy ahí. Unas fotos las he suprimido, las que esta él, no las puedo coger. Pero ha cambiado. Ahora ya no me produce an-

${ }^{10} \mathrm{http}: / /$ www.cartasoh.com/ 
siedad mirarlas, diría que me son indiferentes, no las elijo pero no me molestan.

Ese cambio me produce un "comienzo"; me sorprendo de mi misma por poder hacerlo.

He escogido esta imagen que representa la risa, reirme ahora, ya no me da ansiedad".

Otra participante nos cuenta su experiencia: "en las fotos me veo feliz de pequeñita, aunque hay gente que ya no está: mis abuelos, la comunión. Las fotos de cuando estuve casada. Yo me casé enamorada; tengo sus hijos maravillosos. No cogí las fotos de él tampoco, aunque son parte de mi vida. Al verlas pensaba: ¿que estaba pensando yo para casarme con este hombre?. Creo que no me enteraba de nada en ese momento, hubo un momento de felicidad, pero estaba engañada. Los niños cogen los álbumes, no conocen casi a su padre, y quieren saber quién es su padre”.

"Me he sorprendido al sentarme a verlas (y no evitar) toda la noche acordándome situaciones. Dolor por 15 años de épocas pasadas, años perdidos, aguantando. Me di cuenta que en ese tiempo no hay fiestas familiares, porque evitaba ir para que él no la monte. Me he perdido muchas cosas. Escojo la carta del dibujo de una explosión porque simboliza el dolor de pensar que he desperdiciado mi vida, pero también el de una mariposa que nace: fotos de buscar trabajo sola, con los niños sola. Tranquilidad de ahora y la palabra "adelante".

Otra mujer expresa las emociones que sintió: "tristeza. De pequeña muy bien con mi familia, me gusta mucho esa etapa. Las intente ordenar cronológicamente. Volví a ver fotos de él y sentí su sombra en mi espalda. Mezcla de emociones: rabia, pena... Escojo la carta con la imagen de un arco iris en medio de la tormenta, para expresar cómo lo veo ahora. La palabra "Sabio" porque este trabajo puede ayudar a curar las heridas".

Otra mujer muestra un menor nivel de integración produciendo un desborde de angustia al ser conciente de todo el tiempo que ha vivido situaciones de malos tratos:

"A mi me costó mucho escoger las fotos; me puse fatal. Vi el "Ciclo de mi vida" en las fotos. Fueron 15 años de dolor, tomar contacto con ello y removerme. Estuve mal en la otra sesión, me tuve que ir por ello. En ese momento, en el que sucedió la violencia, no había centros de ayuda. Después, la segunda pareja también me maltrató otra vez. Ahora esta en la cárcel. Las suyas si las rompí. Sigo hasta hoy con juicios". 
En un segundo momento, tras la construcción de la línea de tiempo de manera creativa, en lo que será el cuaderno de artista de cada una, nos dividimos en pequeños grupos comenzando el proceso de la narración de la fotobiografía.

Cada mujer tiene un tiempo marcado por la coordinadora en el que narra en primera persona cada foto y el por qué la escogió. Luego sus compañeras, al final de la narración, le devuelven lo que han percibido y hay una etapa de diálogo. También hay un intento de síntesis, de ver que cosas se repiten en su historia, qué cosas se han querido mostrar de su vida, qué cosas se eliminan o evitan.

Escogemos la narración de esta participante, porque a pesar de la angustia que le provocó la toma de contacto con las fotos y de su historia de violencia, pudo narrarlo en un clima de respeto y apoyo, sacar conclusiones y condensar en algunas fotos claves o "bisagras", los fuertes cambios que se dieron en su vida:

Tras ordenar las fotos de manera cronológica, comenta: "Las fotos empiezan con la familia y la comunión. En la comunión comienzas a crecer. He hecho una división en periodos de 15 años porque tengo 45. De los 30 a 45 fue lo más horroroso. Comienzo con la unión familiar. Continúo con mis hermanos en la parcela, la adolescencia, los animales. Tus amigos. Los sigo conservando todavía.

Mi mejor amiga, luego un grupo más grande de pertenencia, sales de acampadas. Hay amigas del pasado y amigas del futuro...hacemos viajes y comienzan los cambios. Esta foto rompe con el anterior periodo: es en una estación de Paris, y estoy embarazada. Lo simbolizo en una foto donde aparece el signo de alarma: comienzan cambios bestiales en mi vida. (Narra primera pelea que le arremete con su hija recién nacida). Dejo de hacer todo: amigos, familia. Intentas no verlos; hacer lo que él te pide para evitar el conflicto, pero no sirve de nada. Aprendi que este hombre no iba a cambiar.

Ahora en esta foto las personas que más me han apoyado. El camino de Santiago: conoces gente, unas tiran de ti en las cuestas, es para mi "El Camino de la Vida", cómo unos tiran de los otros. (Simboliza con el camino el cambio en su vida).

Sentí angustia al ver que se ha repetido en mi vida la historia de violencia, pero las últimas fotos hablan del cambio, una relación diferente es posible.

Veo el futuro difícil pero ya no estoy sola. Ahora siento tranquilidad. Me siento mejor narrando que en la selección que me angustio el tomar contacto con el tiempo en que el maltrato ha ocupado en mi vida...

He querido mostrar la evolución, la línea de la vida. El primer periodo: la unión familiar, los amigos. La adolescencia turbulenta pero con amigos y acompañada. Hay un cambio radical a partir del embarazo: es una foto que lo simboliza todo. La alarma, la vía: un pasado y un futuro...

El camino de Santiago resume los quince años más duros: subir, bajar, detenerte"...

Otro momento importante de las sesiones que combina fotografía y narración, se daba en las sesiones donde a partir de pequeñas consignas, como "tu mujer ideal", "un día de tu vida", "autorretrato", "un objeto que te represente", comen- 
zaron a traer sus producciones fotográficas y realizábamos el visionado del material con la narración a sus compañeras de lo que habían traído. En esos momentos de narración respetuosa por parte del grupo, de apoyo en el momento de ser necesario, se iban mostrando aspectos de su historia y perfilándose los proyectos personales, centradas en aquellas mujeres a las que "podrían ayudar si llegase su trabajo para prevenir la violencia". En este caso podríamos decir que estaba presente imaginariamente ese espectador a quien iba a llegar su obra, y ellas a su vez identificadas como mujeres que estuvieron atrapadas en la situación de malos tratos.

Mostramos el proceso de una de las mujeres que inauguró las sesiones (un poco desorientada, como todas, acerca de lo que había que hacer y qué había que fotografiar), con la pregunta "Yo tengo un limonero, ¿qué hago le saco fotos?, ¿nos sirve?". A lo largo de los talleres su trabajo se fue perfilando, quedando su proyecto resumido en el título "Los brotes que da la vida". En él sus plantas y sus hijos se fueron convirtiendo en una metáfora de los cambios, el crecimiento, y en esa línea vital, con subidas y bajadas, momentos unos ligados a la vida y otros al dolor. Esta participante, casi desde un inicio, fue aunando las imágenes que iba trayendo a las sesiones al texto escrito que íbamos revisando y compartiendo en las sesiones de escritura: aquí va un extracto del proceso y de sus textos:

"Siempre he tenido plantas, muchas plantas, y animales, gatos sobre todo, desde que tengo uso de razón.

En el pueblo de mi madre, el patio de casa de mi abuela estaba lleno de macetas con geranios que todos los años pintábamos de verde y amarillo, y yo todos los viernes cogía un gatito y me lo traía a Madrid.... al fin de semana siguiente volvía al pueblo...y asi hasta que me regalaron mi primer gato, y luego otro, y ahora tengo dos gatas....y un lorito que vuela por mi casa $y$ habla un poquito. (menos que yo).

Él trabajaba con parques y jardines y también me traía plantas, me regalaba flores, ramos impresionantes y me hice muy amiga de la chica de la tienda de las flores en el mercado de mi casa. Todos los miércoles me compraba un ramo de margaritas y luego...me tomaba un café.

Mi casa parecía un jardín....

Pero... se fueron muriendo, como murieron muchas otras cosas.

Llegó el momento en que me quedé sola, bueno sola no, con mi familia y mis hijos. Lo elegi yo, igual que elegí casarme, igual que ahora he elegido ser feliz...igual que todo lo elegimos.

Entonces compraba algunas veces plantas, pero acababan muriendo como mis relaciones, pero siempre compraba otra y la intentaba cuidar, ¿Porqué no seguian conmigo?

Ahora he empezado una nueva vida, y el limonero está en flor, con sus limones verdes, aún no están maduros, pero saben muy bien, se van poniendo amarillos y sigue floreciendo. El peral está increíble cada día le salen nuevas hojitas y se está llenando de flores, igual que todo el jardín, y el huerto creo 
que crece por las noches, cuando duermo, cuando sueño, y cuando me abrazan. Los abrazos y los besos, hacen florecer todo... ihasta a mí!....me doy cuenta de que a veces sonrío sin ninguna razón, ¿por qué?, Yo también crezco en toda esta maraña de flores, de subidas y bajadas, de sol y frío, de lluvia y resplandor, de invierno y verano.

Realmente mi vida empezó hace casi 7 años. Con altibajos. En ocasiones no me aguantaba ni yo. Con plantas que crecían y morían, pero que volvía a poner en mi vida, en mi salón, en mi despacho, en la cocina.

Mi sueño se está haciendo realidad. No tengo nada material; no tengo propiedades, pero lo que tengo estaba en mis sueños y he decidido cuidarlo todos los días.

Ahora con el sol, el agua, la lluvia, el viento, al amor, el cariño y la dedicación de todos nosotros está en pleno esplendor.....el jardín y nosotros. ¡Como mi vida!”

De la crónica de la sesión destacamos la devolución de la profesora de escritura en sesión, tras leerlo: "Usas la primera persona en el texto y es importante la utilización del tiempo. Se hablan de seres vivos: plantas, animales, todo tiene que ver con la vida. Se habla de un personaje: "él trabajaba con parques y jardines" pero no se desarrolla más pero al decir justo después "las plantas se fueron muriendo", das a entender que la vida lleva aparejada la muerte también. Este es el punto de inflexión del relato: "las plantas mueren". Del PASADO vamos al AHORA y toman protagonismo los SERES VIVOS y describimos la VIDA. Se habla del afecto: "los abrazos y los besos hacen crecer todo". El crecimiento de las plantas tiene que ver con la persona. Importante la evolución de la persona. El crecimiento de la persona paralelo a la evolución del limonero. De amargo y verde, a la maduración.

Luego dices: "pero se fueron muriendo como murieron otras cosas" No nos queda una sensación de contraste, sino de evolución del pasado al presente, hacia el crecimiento. Hay un contraste pero está contado como un crecimiento personal, una evolución".

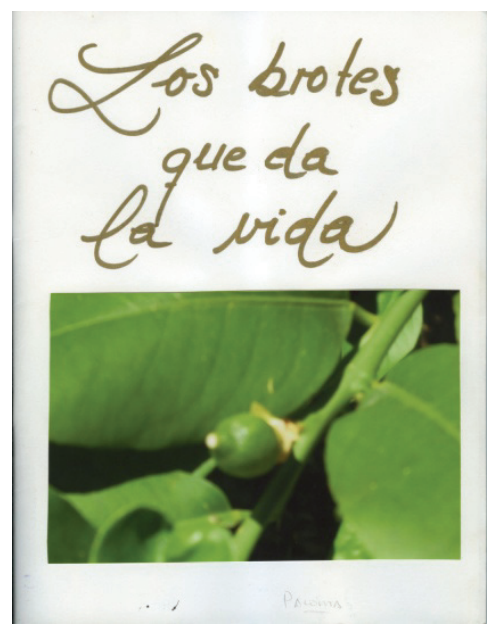

Fig. 1: limonero 
Durante los visionados de las fotos, fueron saliendo aspectos de las historias de violencia, así como la posibilidad de que la violencia ya estuviese en sus vidas desde la infancia. Este es un aspecto significativo, porque algunas participantes, y tomando en cuenta la pregunta de si la situación de violencia estaba superada y formaba parte del pasado, pudieron darse cuenta que faltaba elaborar ese aspecto infantil que al día de hoy les sigue generando emociones fuertes de pena, rabia, ambivalencia.

Una compañera al traer ese aspecto, fue la portavoz de esas situaciones, en la que otras mujeres se sintieron identificadas:

"Esto tiene que ver más con la violencia. Este pájaro de cerámica, mi madre lo adoraba y se lo rompió mi padre. Lo pegamos y ahi está en casa de mi padre, le falta el pico...

La casa de mi padre desde dentro, desde lo que se ve enfrente y desde el suelo. Es una foto indiscriminada, pero luego recordé que de pequeña cuando había broncas yo me tumbaba por ahi en el suelo y veía desde abajo el balcón. La cortina es igual que cuando tenía dos años. Pensaba qué hacía de pequeña cuando me ponía ahi y me echaban la bronca. Esto es lo que veía de peque$\tilde{n} a ”$.

Otra mujer trae el aspecto infantil y refiere: "cuando comencé a venir a terapia no podía ni ver a mi padre, no iba a su casa. Me di cuenta de que estaba enfadada porque tampoco se había portado bien con mi madre, cuando yo era pequeña".

Entre fotos, su visionado y narración, se va perfilando qué proyecto fotográfico haría cada mujer. Los debates iban en torno a lo vivido en las situaciones de violencia con sus parejas, y sus ganas de que otras mujeres a partir de sus fotos puedan darse cuenta de qué es la violencia para que no tengan que pasar lo mismo. Algunas mujeres querían señalar claramente los indicadores de violencia con mensajes directos sobre lo que es violencia. Este es un extracto de un visionado de una de las mujeres:

"cuando estaba con él deje de cantar, hacer musicales, y al terminar con él he vuelto a cantar. A mi me gustaba dibujar, y como todo lo criticaba... yo le dije voy a dibujar quieras o no. Luego me la lío pero me dio lo mismo.

Quería que dejase de estudiar, y este es uno de los libros que me compre para seguir estudiando.

A mi me decía que mi nariz es un martillo y me hacia ruidos, vas a taladrar la acera. El cartel dice no eres fea, por eso puse el martillo.

Me criticaba que no vestía bien. Por eso es poner claramente "No lo eres". 


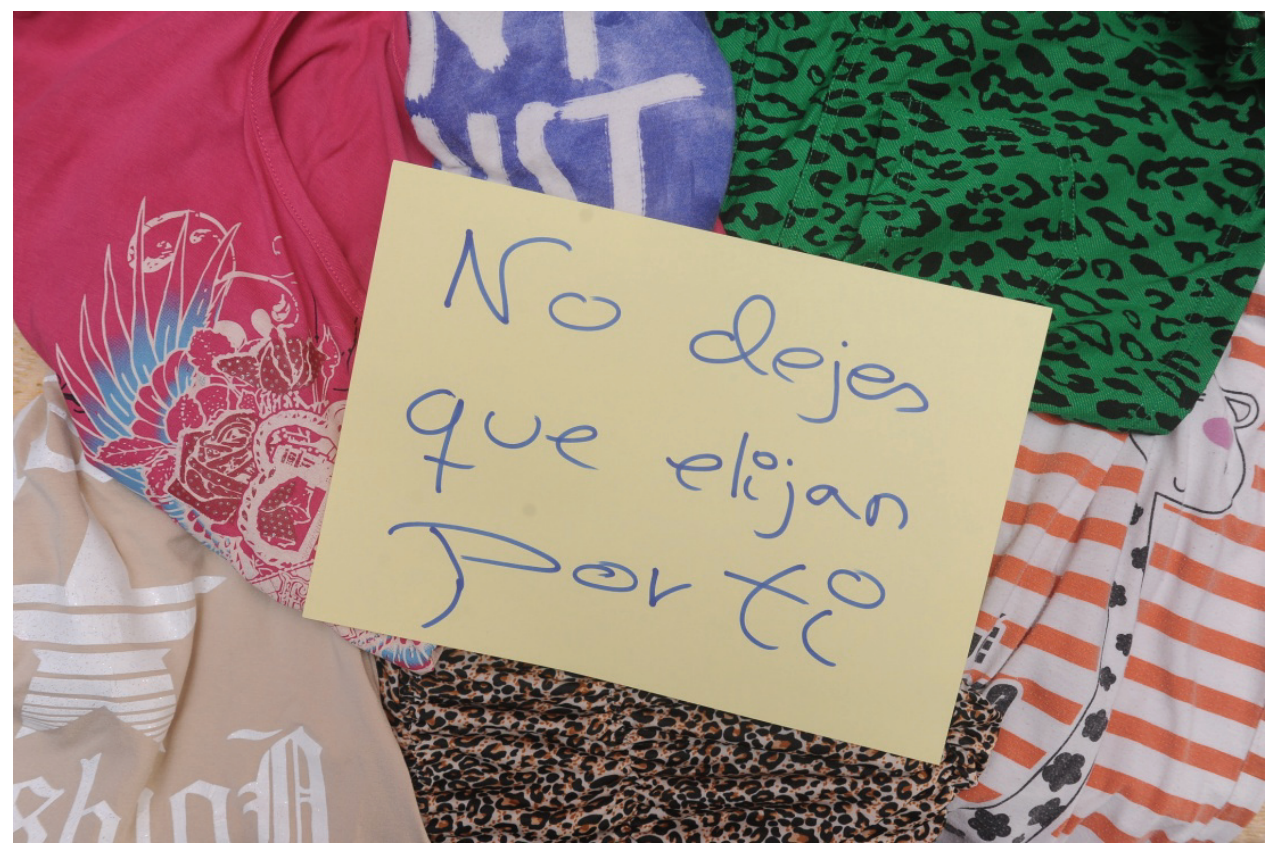

Fig. 2: POSIT

Otras fueron dándose cuenta, por ejemplo que si mostraban todo lo que podían hacer en libertad, sin control ni temor, como pautas de autocuidado y disfrute, estarían dando el mismo mensaje de una manera más indirecta:

"El momento del café de la mañana y mi ventana: mi barrio.

Maquillándome, arreglándome el pelo.

Mi lunar característico que de pequeña me lo quería quitar y ahora esta de moda.

El escote que a mi me encanta. Me hice una foto al escote.

Esto es el parque, las pipas y una lata de coca cola, momento de relax con mi amigo. Esto no lo cambio por nada...."

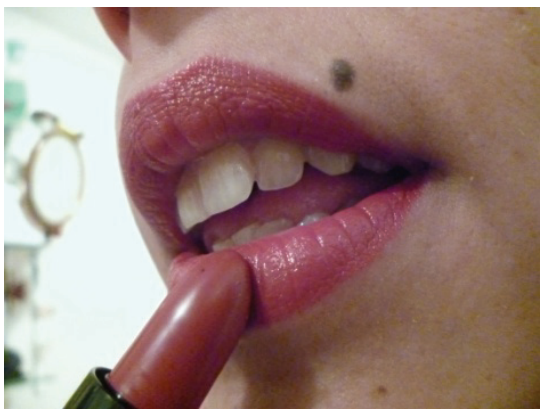

Fig. 3: Autocuidado

Arteterapia: Papeles de arteterapia y educación artística para la inclusión social 
Tomando en cuenta la definición de creatividad, la posibilidad de imaginar otros mundos y situaciones alejándonos más de lo concreto y el mundo real, destacamos una de las participantes que comenzó a ficcionar en sus fotos a partir de la consigna: "Mi mujer ideal". Su contestación fue: "mi mujer ideal soy yo, por eso me quiero vestir de super heroína", y se realizó una serie de retratos con la ayuda de la coordinadora donde ella fue la protagonista. Representó al maltratador con un muñeco. Aquí va el origen de su idea: "Me compré un muñeco, porque cuando me duchaba lo tenía ahi. Intimidad cero. Y me compre este muñeco con cara de macarra pegón. Me he comprado una barbie chunga, las que quedan calvas. Quiero crear historias (risas y sorpresas de sus compañeras)"”

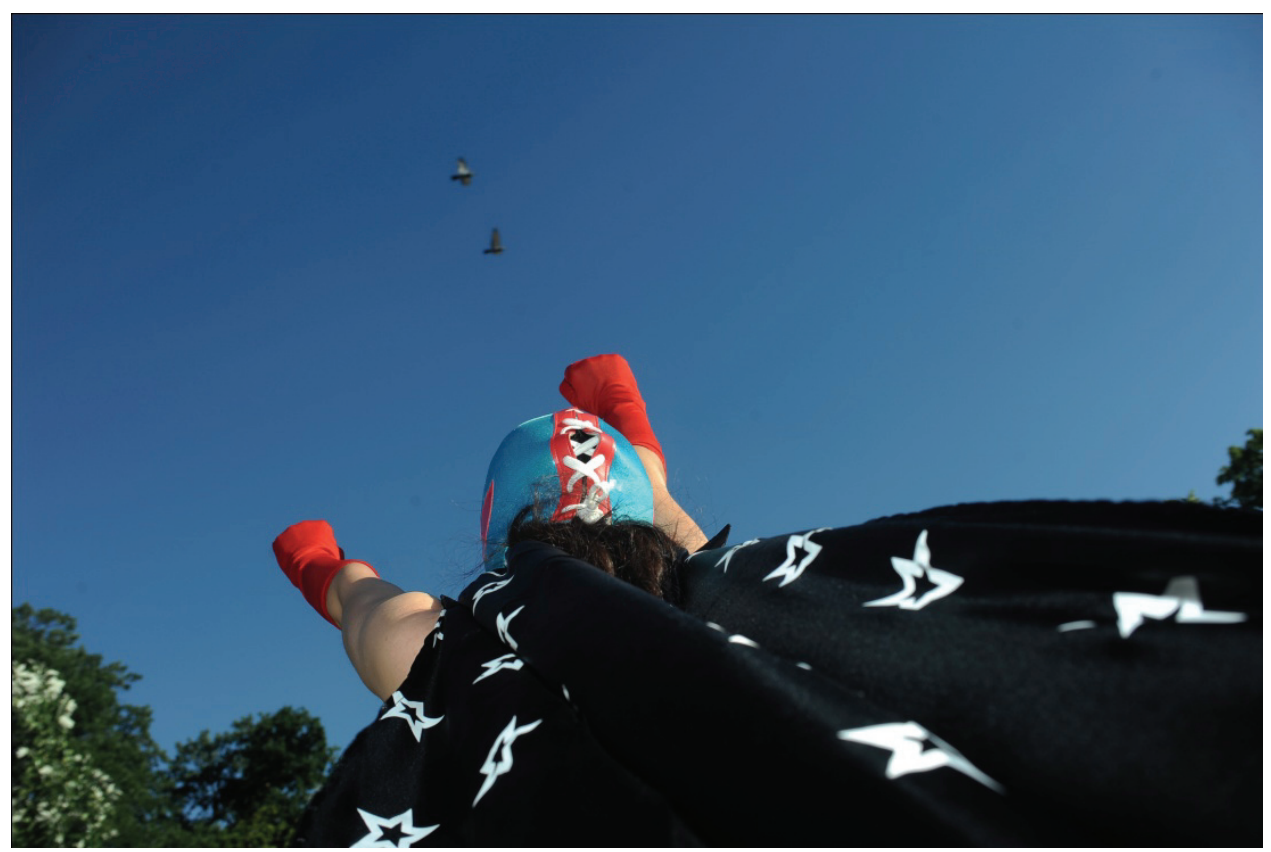

Fig. 4: Heroina

\section{Resultados del proceso}

En la valoración de las mujeres en relación al proceso destacan en la evaluación cuantitativa:

En un $87 \%$ han afirmado: "siento que el proceso hecho en el taller me ha ayudado a auto observar mi vida y reflexionar sobre ella".

En un 90\% opinan: "creo que el trabajo que hemos hecho a lo largo de las sesiones me ha ayudado a ver y comprender la historia de violencia que he vivido de una manera diferente a como la entendía o vivía antes".

En un $85 \%$ afirman: "veo el pasado como algo que me ha marcado pero de lo que he aprendido y me ha hecho cambiar en el presente". 
En un $85 \%$ afirman: "creo que el proceso de buscar imágenes y narrar acerca del aquí y ahora y futuro, ha contribuido a focalizar la atención en ello y centrarme más en mi potencial "en lo que soy capaz y deseo hacer".

En cuanto a la valoración cualitativa destacamos, su palabra:

-Me siento "hasta anciana" en esto de superar cosas, de buscar recursos, de hablar de ello, pero no por ello voy a dejar de hacerlo, de repetirlo, de intentarlo, de buscarlo. El taller me ha ayudado más si cabe a seguir caminando siempre.

-Reflexionar sobre una misma es dificil, pero sí que el taller me ha llevado a ello, aunque no me lo propusiese. A veces es doloroso, pero me hace consciente de todo lo vivido; del presente y que nosotras mismas decidimos. Siempre que haga una foto me acordare del taller.

-Yo sé que todavía estoy dentro del túnel. Tengo muchas cosas a mi alrededor que me cuestan superar, y que no están cicatrizadas, pero sé que vale la pena vivir de otra manera.

-El hecho compartir las historias de violencia me hace sentir; que no estoy sola. Siempre me he dado cuenta de lo importante de tener puntos de vista de distintas mujeres que habian pasado por el mismo infierno, de la terapia grupal. Ahora gracias al taller me he dado cuenta que realmente lo tengo superado, no siendo más que otra etapa de mi vida.

-Me ha descubierto un nuevo yo. Mi nuevo yo siente, ama, comprende, entiende, juzga...todo con una visión distinta y sobretodo positiva. Siempre pienso que lo que no te mata te hace más fuerte. De lo malo se aprende muchísimo.

-La historia de violencia sí la veo como algo del pasado, y creo que a lo largo de los años y con muchos esfuerzos y tras múltiples intentos y caídas, he aprendido bastante. He cambiado mucho y no soy la misma de entonces, estoy más fuerte y tengo más claro lo que quiero y cómo buscar el bienestar. Pero el taller me ha hecho reencontrarme con sensaciones de agobio que no he sabido manejar bien, que no sé muy bien explicar qué pienso...

-Cambio de pensar que lo tenía todo superado, a darme cuenta de que no lo tenía superado. A ver ahora qué es realmente lo que me importa y quiero en mi vida. Yo no era capaz de ir a lugares cercanos donde vive el agresor y a través de las fotos me he ido moviendo. Y ahora me doy cuenta que puedo ir si voy con otra fuerza. Me costó la foto-biografia, seleccionar las fotos de infancia porque ha sido muy dura y no soy capaz de verlas porque me pongo mal. La experiencia de contarlo me ha ayudado porque nunca lo he contado excepto a mi pareja actual. 
-Con la línea del tiempo en fotos, al principio me resultó doloroso realizarlo, pero después comprobé que para transmitir todas aquellas emociones y poder decir a los demás cómo me sentía en aquel momento, era necesario abrir la herida para comprobar que estaba cerrada, pese a tener altibajos. El diario de artista quise enfocarlo desde el punto de vista de "esta es mi vida ahora" (que creo era lo que se pedía) pero a su vez me hizo pensar y reflexionar en cómo estaba antes y por qué siendo como soy me dejé tratar así. Me siento fuerte porque sé que después de esta terapia, puedo afrontar por completo el tema de la violencia de género. Con ganas, esfuerzo y tiempo se puede hacer, y que lo que no queríamos hacer por miedo a sufrir de nuevo, te hace darte cuenta de si tenías ese problema o no superado.

En cuanto al proceso creativo:

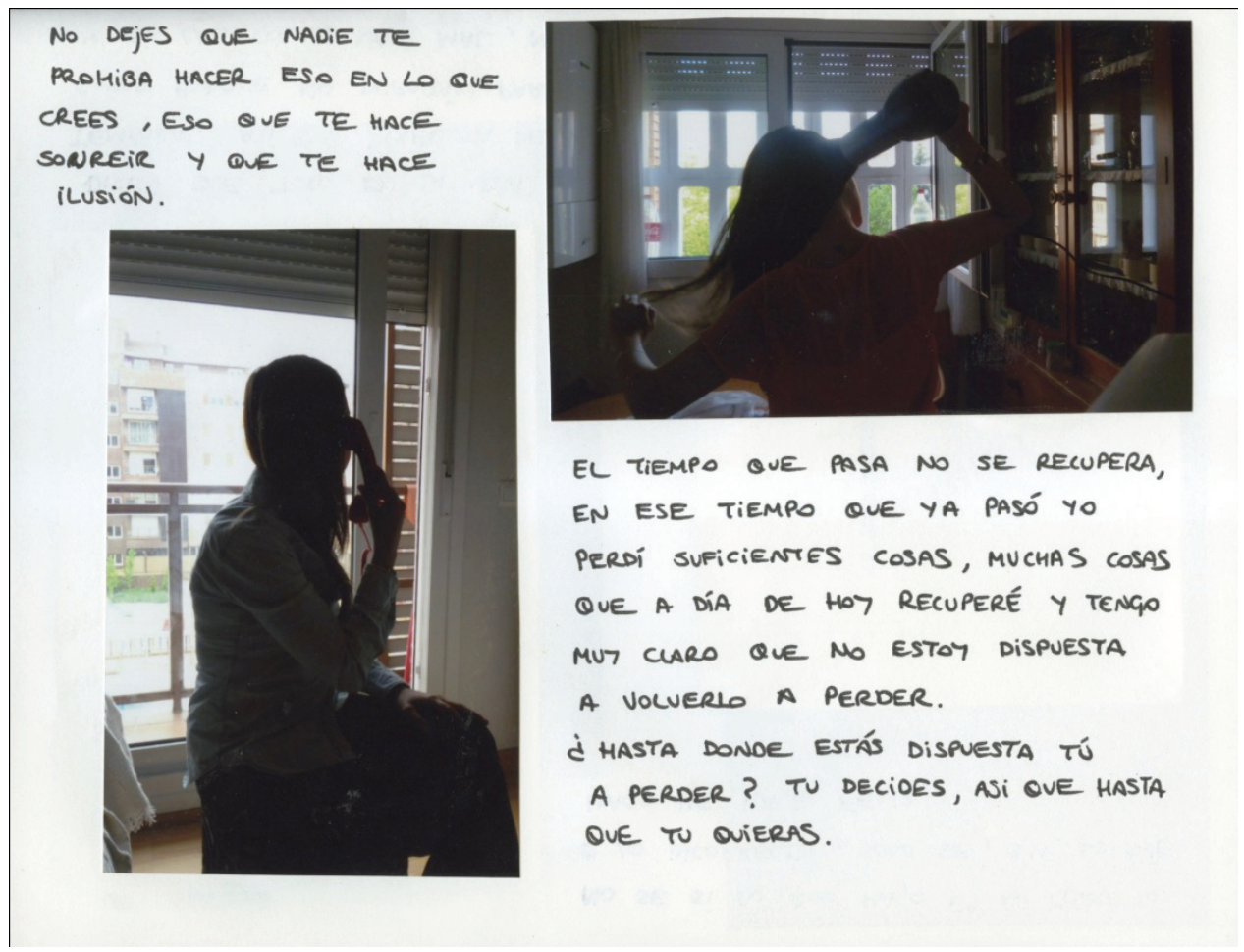

Fig. 5: cuaderno artista. 
El 82\% ha señalado: "ha ido creciendo la motivación para utilizar la cámara fotográfica y pensar posibles imágenes de tu tema a medida que avanzaban los talleres".

El 86\% ha afirmado: "creo que las herramientas aprendidas de escritura y fotografía son útiles para expresar mis emociones y sentimientos".

En relación a la pregunta “¿qué foto habla más de ti misma?”, destacamos:

"supongo que una que había hecho sobre la ventana de casa de mi padre a través de la cortina, porque es la casa y las vistas de donde me crié, donde fui muy feliz y donde un día todo se rompió. Donde me siento segura y donde siempre vuelvo cuando algo va mal, pero también donde se rompió mi familia y donde empecé a sentirme sola, abandonada y merecedora de los castigos y regaños".

"la que salgo de casa con la mochila me identifica porque yo antes no podía salir y hacer lo que me gustaba".

"cualquiera de las fotos hablan de mi. Porque a través de ellas, aunque creía que no era posible, ha salido una parte de mi vida. En estos años he crecido como persona igual que mis plantas y mis hijos"..

"la foto que sale una mesa en un parque con una lata de coca cola, tabaco, donuts, pipas... porque muestra varias de las cosas que me gusta hacer a diario y siempre en compañia de amigos".

Como resumen estas valoraciones:

"Con la fotografia se puede hablar y mucho. Cada una haciendo fotos ha llegado a lugares muy distintos. Pero realmente lo que más me ha sorprendido ha sido, que una fotografia te hiciese hablar como me ocurrió a mi. Mediante la escritura he logrado sacar muchas cosas que tenia dentro. Amigos que han seguido todo este proceso y que no lo entendían porque creían que era un curso de fotografia, se han asombrado del proyecto que habéis llevado a cabo y les encantaría ir a la exposición. También me ha dado la posibilidad de tener un momento de ocio que en mi casa todos han respetado: mis hijos y mi pareja. Han pensado que era importante para mi y me han apoyado mucho".

"He disfrutado de cada taller que hemos realizado. Dándonos cuenta de que hay cosas que me gustan más (como hacer fotos) y otras menos (como escribir), pero que las decisiones que he tomado y sigo tomando en mi vida son correctas. Intento cada día conocerme un poco más y disfrutar de la vida de la manera que mejor me parece".

Podemos afirmar que el proceso de Enfocadas en voz de las participantes da cuenta de lo que muy bien autores expresan: "No podemos cambiar lo que ocurrió, pero sí podemos cambiar el sentido y significado que damos a lo vivido" (Yolanda Calvo, 2012). 


\section{Referncias bibliográficas}

SANZ, F. (2007): La fotobiografía: Imágenes e historias del pasado para vivir con plenitud el presente, México, Editorial Kairos.

SANZ, F. (1995): Los vínculos amorosos: amar desde la identidad en la terapia del reencuentro, México, Editorial Kairos.

SIEGEL, D. (2001): Mindsight: la nueva ciencia de la transformación personal, Barcelona Editorial Paidos.

SIEGEL, D. (2001): La mente en desarrollo, Editorial Desclee.

MIGALLON P. \& GALVEZ, B. (2012): Los grupos de mujeres: metodología y contenido para el trabajo de la autoestima, Madrid, Instituto de la Mujer.

PACE, P (2009): Lifespan Integration (Integración del Ciclo Vital): conectando los estados del Ego a través del tiempo, España.

HEURA POSADA PIE (2011) Lenguaje Visual contemporáneo de la oralidad a la imagen". En revista Hapax n 4, 103-112. Sociedad de estudio de lengua y Literatura. Universitat de Barcelona.

MONSERRAT JAVIER: Teoría de la mente en Antonio R Damasio. Universidad Autónoma de Madrid.

WEISER JUDY: La fotografía como herramienta terapéutica. En pagina web: http://www.phototherapy-centre.com/home.htm

CHARAF MARIANA (2012) Relajación creativa: técnicas y experiencias. Educrea, 2a Edición. Santiago de Compostela Abril 2012 